\title{
Traumatic Atlantoaxial Lateral Subluxation With Chronic Type II Odontoid Fracture: A Case Report
}

\author{
ARIF MUSA, MS, ${ }^{1}$ SAIF ALDEEN FARHAN, MD, ${ }^{2}$ YU-PO LEE, $M D,{ }^{2}$ BRITTANY URIBE, BS, ${ }^{3}$ \\ P. DOUGLAS KIESTER, MD, $\mathrm{PhD}^{2}$ \\ ${ }^{I}$ School of Medicine, Wayne State University, Detroit, Michigan, ${ }^{2}$ Department of Orthopaedic Surgery, University of California Irvine Medical Center, \\ Orange, California, ${ }^{3}$ School of Osteopathic Medicine, Rowan University, Stratford, New Jersey
}

\begin{abstract}
Background: We report a case of an elderly patient who was diagnosed with lateral atlantoaxial subluxation with type II odontoid fracture, an extremely uncommon upper cervical spine injury that has not been previously reported in the literature to the knowledge of the authors.

Methods: An 87-year-old male reported to the emergency room following a syncopal episode after sustaining a fall. He complained of dizziness, fatigue, disruption of vision and audition, and worsening neck pain. Computed tomographic scans were positive of partial dislocation of the $\mathrm{C} 1$ relative to $\mathrm{C} 2$ and chronic fracture of dens classified as type II according to the Anderson and D'Alonzo classification system. Magnetic resonance imaging further revealed large fracture pannus tissue at the level of the dens, reducing the space in the spinal cord. There was no evidence of spinal cord injury. Atlas-axis fusion with instrumentation was performed to manage the injury. A review of the classification, occurrence, and management of upper cervical spine surgeries was performed.

Results: An acute injury to a previously unrecognized type II odontoid fracture with partial C1-C2 dislocation was identified as a rare upper cervical spine injury and classified based on the Anderson and D'Alonzo and Fielding and Hawkins classification systems. The decision was made to perform instrumented spinal fusion by inserting mass screws into $\mathrm{C} 1$, pars screws into $\mathrm{C} 2$, and locking rods to realign the vertebral bodies and address the atlantoaxial instability. Follow-up scans indicated good postsurgical reduction and fixation, including resolution of the pannus overgrowth without direct intervention.
\end{abstract}

Conclusions: Lateral atlantoaxial subluxation with chronic type II fracture of the dens constitutes a rare injury of the upper cervical vertebrae. Posterior instrumented spinal fusion was used to effectively manage the injury, leading to reabsorption of retro-odontoid pannus tissue.

Cervical Spine

Keywords: atlantoaxial subluxation, $\mathrm{C} 2$ fracture, odontoid fracture, retro-odontoid pannus

\section{INTRODUCTION}

Lateral subluxation of the atlas $(\mathrm{C} 1)$ and axis (C2) associated with type II odontoid fracture of the dens is very rare. Fractures of the dens, however, are the most common injury to the $\mathrm{C} 2$ vertebra. ${ }^{1}$ Of these, type II fractures are the most prolific. $^{2}$ Among combined injuries of the cervical spine, rotational atlantoaxial subluxation with type II dens fracture were reported in $<0.3 \%$ of cases. ${ }^{3}$ After conducting a literature search of PubMed, Scopus, Google Scholar, and relevant reference lists, we found only 1 other published case of lateral $\mathrm{C} 1$ subluxation. ${ }^{4}$ Therefore, the reported case of lateral subluxation of $\mathrm{C} 1$ relative to $\mathrm{C} 2$ is a rare injury. Traumatic atlantoaxial dislocation is an often lethal injury involving atlas-axis fractures, fracture of odontoid process, and/or other cervical spine fractures that result from high-velocity trauma. ${ }^{5}$ Furthermore, fractures of the odontoid process are usually more common in the elderly and may go unnoticed due to a lack of neurological deficit. ${ }^{6}$ Odontoid fractures are known to predispose toward atlantoaxial instability. ${ }^{7}$ In this case, the type II fracture of the dens was an old injury. Retroodontoid pannus tissue, which was discovered in the spinal canal at the level of the dens, had significantly narrowed the canal. Pannus overgrowth is of concern due to the potential for inducing spinal stenosis and consequent myelopathy. ${ }^{8}$ Posterior instrumented fusion has been reported to effectively correct these injuries and lead to dissolution of pannus tissue..$^{9-10}$ The injury was treated by initial stabilization with hard collar, followed by posterior 
fusion with pedicle screws, pars screws, and locking rods.

\section{CASE REPORT}

In July 2016, an 87-year-old man was admitted to the emergency room with a chief complaint of syncopal fall in the shower. The patient reported dizziness and fatigue, and the physical exam revealed disruption of visual and auditory perception. He also noted worsening neck pain that had begun after a fall he had sustained in December 2015. His past medical history included diabetes mellitus, hypertension, liver cirrhosis, and atrial fibrillation. Radiographic evaluation revealed a chronic odontoid fracture identified as type II according to the Anderson and D'Alonzo classification system. ${ }^{1}$ Computed tomography of the cervical spine also revealed an acute nondisplaced fracture of the right $\mathrm{C} 2$ transverse process involving the transverse foramen (Figure 1).

Significant subluxation $(7 \mathrm{~mm})$ of $\mathrm{C} 1$ and the odontoid tip was discovered to the right relative to C2. It was possible that the initial fall in December 2015 produced the fracture in the odontoid process, which is known to predispose toward atlantoaxial instability. ${ }^{7}$ Magnetic resonance imaging of the cervical spine was performed to investigate the potential of spinal cord injury (SCI). Findings were consistent with a chronic unstable $\mathrm{C} 2$ dens fracture with a large pannus at the dens level in the spinal canal (Figure 2). Although the space available for the spinal cord was significantly reduced, the spinal cord was not under compression, and results were negative for SCI.

His neck was initially stabilized with a hard collar. Posterior pedicle screw fixation of $\mathrm{C} 1-\mathrm{C} 2$ with bone graft fusion has been recommended as a safe and effective surgical treatment of atlantoaxial dislocation associated with old odontoid fracture. ${ }^{9}$ We performed C1-C2 fusion with instrumentation with careful reduction of the dens in both planes under $\mathrm{C}$-arm control. Postoperative $\mathrm{x}$-rays indicated improved atlantoaxial alignment and reduction of the subluxation, which included improvement in the alignment of the odontoid fracture. There were no intraoperative complications, and the patient's hospital stay was uncomplicated. Follow-up x-rays at 1.5 years after surgery revealed adequate fixation (Figure 3). The patient had full range of motion, no functional restrictions, and no lingering neck pain.
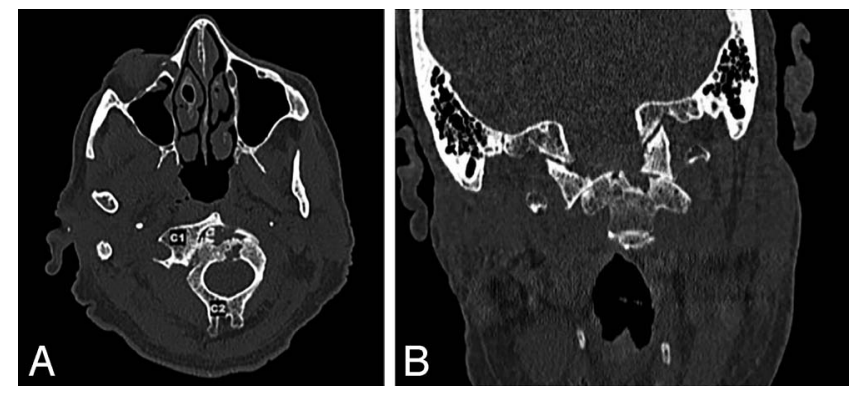

Figure 1. Atlantoaxial subluxation and chronic odontoid fracture. Computed tomographic (CT) scan showing fracture of the $\mathrm{C} 2$ transverse process and subluxation of $\mathrm{C} 1$ relative to $\mathrm{C} 2$ (A). CT scan showing old type II odontoid fracture $(B)$

\section{DISCUSSION}

\section{Literature Review}

We conducted a review of the literature pertaining to traumatic cases of odontoid fractures with concomitant atlantoaxial dislocation by searching the following databases: PubMed, Scopus, and Google Scholar. Reference lists were also searched for relevant articles. We identified several case reports and case series describing the occurrence and management of combined $\mathrm{C} 1-\mathrm{C} 2$ dislocation and fracture of the dens. ${ }^{4,9,11-24}$ Corner described 2 of the earliest cases of rotatory dislocation of $\mathrm{C} 1$ relative to $\mathrm{C} 2$ with accompanying fractures of the odontoid process. ${ }^{25}$

\section{Classification}

Odontoid fractures are classified according to the Anderson and D'Alonzo system, which delineates 3 fracture types (Table 1). ${ }^{1,26}$ Atlantoaxial subluxation may be translational, rotatory, or distractive and is commonly classified according to the Fielding and Hawkins criteria (Table 2). ${ }^{15,26,27}$ A fifth category was described by Levine and Edwards. ${ }^{26,28}$ For this case, the partial translational atlantoaxial luxation could not be classified according to the Fielding and Hawkins criteria, but the associated fracture of the dens was determined to be type II based on the Anderson and D'Alonzo system. Furthermore, the presence of pseudotumor pannus tissue was confirmed within the spinal canal at the level of the dens. Retro-odontoid pannus refers to a granulation tissue frequently encountered in cases of inflammatory disease, such as rheumatoid arthritis, but may also occur in noninflammatory cases. ${ }^{29}$ If left unchecked, retro-odontoid pannus may lead to spinal stenosis and myelopathy. ${ }^{8}$ 

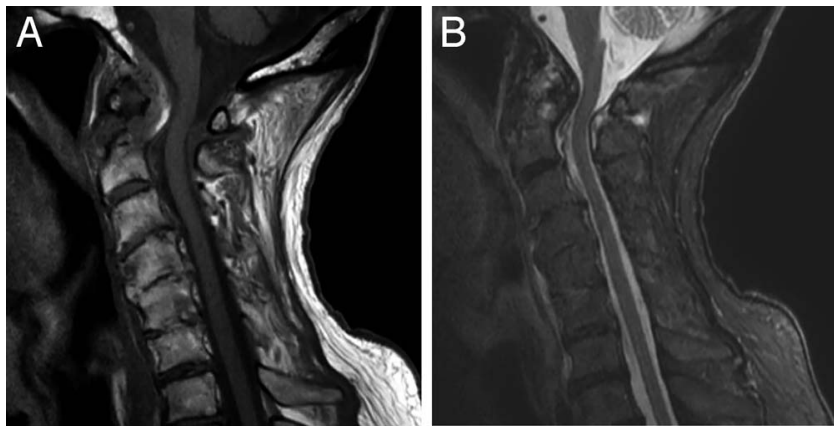

Figure 2. Retro-odontoid pannus tissue. T1-weighted magnetic resonance image of spine displaying retro-odontoid pannus (A). T2-weighted scan showing old type II odontoid fracture (B).

\section{Prevalence}

Traumatic atlantoaxial dislocation is an often lethal injury involving atlas-axis fractures, fracture of odontoid process, and/or other cervical spine fractures that result from high-velocity trauma. ${ }^{5}$ Traumatic atlantoaxial dislocation may occur with concurrent fracture of the odontoid process. ${ }^{11-12,15-19,22-24}$ However, C1-C2 subluxation has also been identified in patients with old odontoid fractures. ${ }^{9,13,20,21}$ Fuentes et $\mathrm{al}^{13}$ reported a case of posterior subluxation associated with an old type II odontoid fracture. $\mathrm{Li}$ et $\mathrm{al}^{21}$ described a patient with dorsal subluxation and a chronic type II dens fracture. Both type II and type III odontoid fractures have been associated with C1C2 dislocations along the antero-posterior axis. ${ }^{9}$ Our case of acute lateral atlantoaxial subluxation with chronic type II odontoid fracture has not been previously reported in the literature.

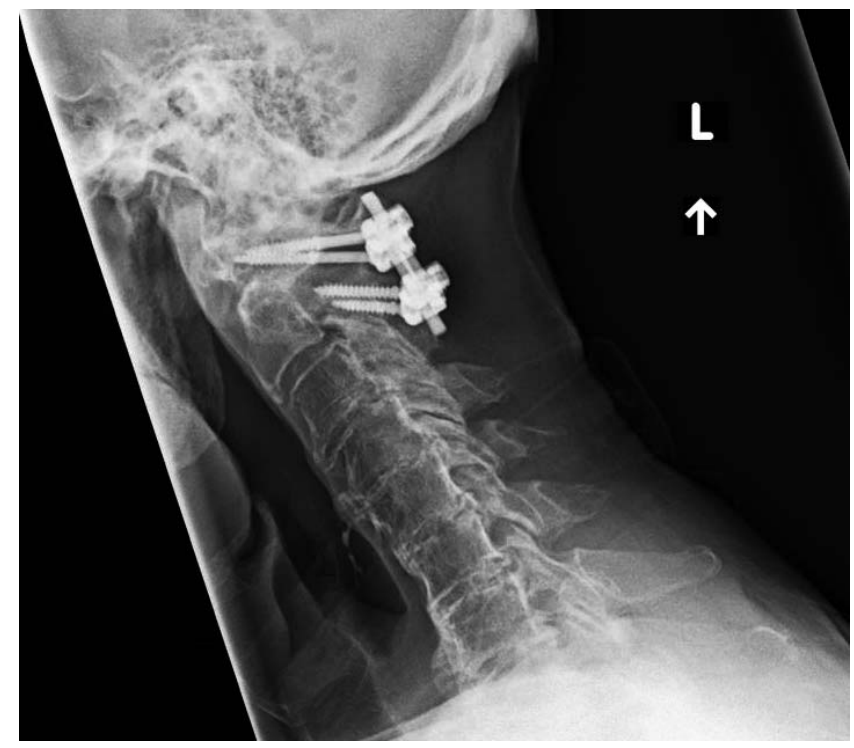

Figure 3. Postoperative images. X-ray demonstrated adequate fixation of instrumentation.
Table 1. Anderson and D'Alonzo classification of odontoid fractures.
Type I

Type II

Type III
Fracture at the dorsal tip of the odontoid process Fracture of the odontoid process at the junction of the dens and $\mathrm{C}^{4,11,13,15,16,20-24}$

Fracture of $\mathrm{C} 2$ below the odontoid process ${ }^{12,17,19}$

\section{Management}

Immobilization remains controversial, particularly in the case of type II odontoid fractures with concomitant C1-C2 fracture. ${ }^{2,30}$ Conversely, immobilization via collar is preferred in the elderly, but surgery may be required in the presence of significant instability. ${ }^{31}$ In this case, given the atlantoaxial instability, spinal stenosis secondary to pannus overgrowth, and myelopathy secondary to cervical spinal stenosis, surgery was performed. Posterior screw fixation of C1-C2 with bone graft fusion has been demonstrated as a safe and effective surgical management of atlantoaxial subluxation associated with old dens fractures. ${ }^{9}$ However, fixation of $\mathrm{C} 1-\mathrm{C} 2$ with the transarticular screw technique carries the risk of spinal cord injury, nerve injury, or injury to the nearby vertebral artery. ${ }^{32}$ Moreover, the vertebral artery may erode with age such that it is directly in the path of the screw. Biomechanical testing has shown that a $\mathrm{C} 1$ lateral mass screw with a $\mathrm{C} 2$ pars screw construct allows an average of 0.6 degrees more motion than does a $\mathrm{C} 1$ C2 transarticular screw. ${ }^{33}$

As a result, for this case it was decided to proceed with fusion by inserting lateral mass screws into $\mathrm{C} 1$ and pars screws into $\mathrm{C} 2$ and to place locking rods, similar to the technique first described by Goel et al. ${ }^{32-34}$ Intraoperative fluoroscopy was performed to ensure accurate placement of screws (Figure 4).

Reabsorption of pannus tissue and resolution of clinical symptoms has been reported in patients with atlantoaxial instability or subluxation following correction. ${ }^{29}$ For example, Shah et al ${ }^{10}$ reported 2 cases of atlantoaxial instability with retro-odontoid pannus tissue that resolved in the immediate postoperative period following surgical correction

Table 2. Fielding and Hawkins classification of atlantoaxial subluxation.

Type I Rotatory displacement without anterior displacement; pivots about the odontoid process

Type II Rotatory displacement with anterior displacement (3-5 $\mathrm{mm})$; pivot about 1 facet

Type III Rotatory displacement with anterior displacement (>5 mm)

Type IV Rotatory displacement with posterior displacement ${ }^{11,19,22}$ Type $\mathrm{V}^{\mathrm{a}} \quad$ Posterior luxation (bilateral) ${ }^{23}$

${ }^{\mathrm{a}}$ Discussed by Levine and Edwards. 


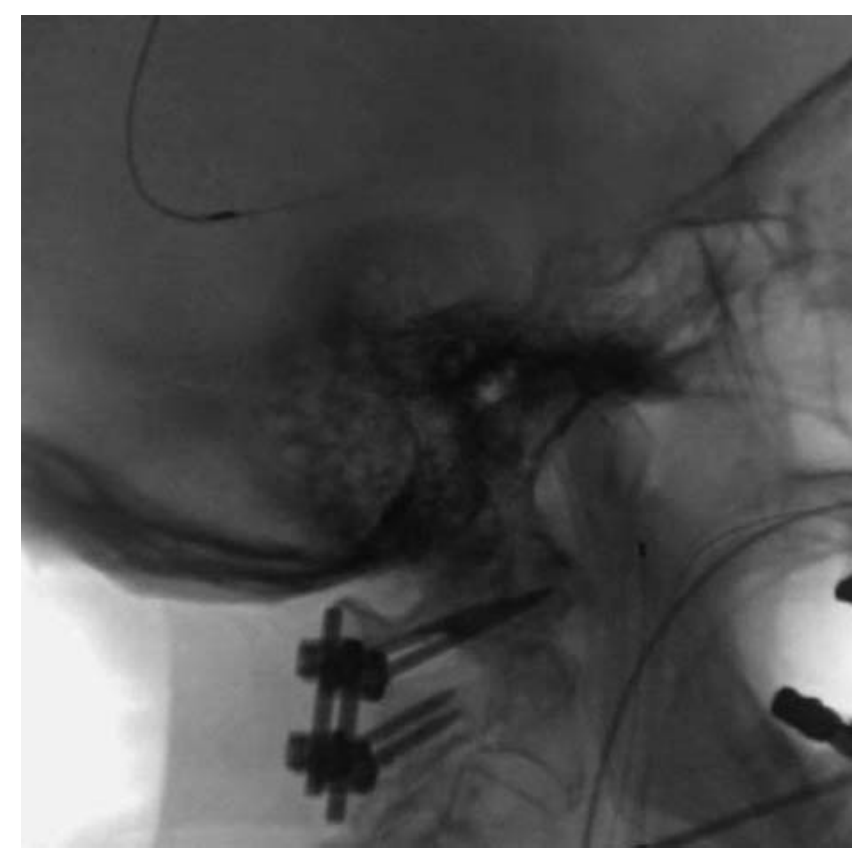

Figure 4. Intraoperative images. Fluoroscopic image of cervical spine demonstrating accurate fixation.

of the instability. Barbagallo et $\mathrm{al}^{29}$ reported gradual progressive reabsorption with disappearance at 6 to 13 months in 3 cases and significant resolution of pannus at 14 months in 1 case. It must be noted that in the 2 previously mentioned studies, pannus reabsorption occurred not with direct intervention but rather from correction of the underlying atlantoaxial instability.

\section{CONCLUSIONS}

Traumatic atlantoaxial subluxation with fracture of the dens is an exceedingly uncommon upper cervical spine injury. Lateral subluxation with an accompanying chronic type II odontoid fracture is rarer still. Posterior instrumented fusion was successful in addressing this traumatic injury and resulting in resolution of pannus tissue.

\section{REFERENCES}

1. Anderson LD, D'Alonzo RT. Fractures of the odontoid process of the axis. J Bone Joint Surg Am. 1974;56(8):16631674.

2. Jaiswal AK, Sharma MS, Behari S, Lyngdoh BT, Jain S, Jain VK. Current management of odontoid fractures. Ind $J$ Neurotrama. 2005;2(1):3-6.

3. Gleizes V, Jacquot FP, Signoret F, Feron JM. Combined injuries in the upper cervical spine: clinical and epidemiological data over a 14-year period. Eur Spine J. 2000;9(5):386-392.

4. Lenehan B, Guerin S, Street J, Poynton A. Lateral C1-C2 dislocation complicating a type II odontoid fracture. $J$ Clin Neurosci. 2010;17(7):947-949.

5. Suchomel P, Fric R. Acute traumatic atlantoaxial dislocation (AAD) in adults. In: Suchomel P, Choutka O, eds. Reconstruction of Upper Cervical Spine and Craniovertebral Junction. Berlin: Springer; 2011:215-218.

6. Avila-Guerra M. Chronic neck pain associated with an old odontoid fracture: a rare presentation. Case Rep Emerg Med. 2013:372723. https://doi.org/10.1155/2013/372723.

7. Yang SY, Boniello AJ, Poorman CE, Chang AL, Wang S, Passias PG. A review of the diagnosis and the treatment of atlantoaxial dislocations. Global Spine J. 2014;4(3):197-210.

8. Lagares A, Arrese I, Pascual B, Gòmez PA, Ramos A, Lobato RD. Pannus resolution after occipitocervical fusion in a non-rheumatoid atlanto-axial instability. Eur Spine J. 2015;15(3):366-369.

9. Qi L, Li M, Zhang S, Si H, Xue J. C1-C2 pedicle screw fixation for treatment of old odontoid fractures. Orthopedics. 2015;38(2):94-100.

10. Shah A, Jain S, Kaswa A, Goel A. Immediate postoperative disappearance of retro-odontoid "pseudotumor." World Neurosurg. 2016;91:419-423.

11. Autricque A, Lesoin F, Villette L, Franz K, Pruvo JP, Jomin M. Fracture of the odontoid process and C1-C2 lateral luxation. Two cases. [In French]. Ann Chir. 1986;40(6):397-400.

12. Pryzbylski GJ, Welch WC. Longitudinal atlantoaxial dislocation with type III odontoid fracture. Case report and review of the literature. J Neurosurg. 1996;84(4):666-670.

13. Fuentes S, Boillot P, Palombi O, Ducolombier A, Desgeorges M. Traumatic atlantoaxial rotatory dislocation with odontoid fracture. Spine (Phila Pa 1976). 2001;26(7):830834.

14. Goel A, Kulkarni AG, Sharma P. Reduction of fixed atlantoaxial dislocation in 24 cases: technical note. $J$ Neurosurg Spine. 2005;2(4):505-509.

15. Spoor $\mathrm{AB}$, Diekerhof $\mathrm{CH}$, Bonnet $\mathrm{M}$, Oner $\mathrm{FC}$. Traumatic complex dislocation of the atlanto-axial joint with odontoid and C2 superior articular facet fracture. Spine (Phila Pa 1976). 2008;33(19):E708-E711.

16. Hopf S, Buchalla R, Elhöft H, Rubarth O, Börm W. Atypical dislocated dens fracture type II with rotational atlantoaxial luxation after a riding accident. [In German]. Unfallchirurg. 2009;112(5):517-520.

17. Oh JY, Chough CK, Cho CB, Park HK. Traumatic atlantoaxial rotatory fixation with accompanying odontoid and C2 articular facet fracture. $J$ Korean Neurosurg Soc. 2010;48(5):452-454.

18. Buchvald P, Barsa P, Suchomel P. Odontoid fracture combined with lateral atlanto-axial dislocation. Report of two cases. [In Czech]. Acta Chir Orthop Traumatol Cech. 2012;79(5):459-462.

19. Moreau PE, Nguyen V, Atallah A, Kassab G, Thiong'o MW, Laporte C. Traumatic atlantoaxial dislocation with odontoid fracture: a case report. Orthop Traumatol Surg Res. 2012;98(5):613-617.

20. Zhang K, Xu J, Wang Q, et al. Treatment of dens fractures with posterior atlantoaxial dislocation with transoral atlantoaxial reduction plate surgery: a case report and introduction of a novel treatment option. Spine (Phila Pa 1976). 2012;37(7):E451-E455.

21. Li Z, Zhang H, Li X, Liu X, Huang Y, Wu A. Traumatic 
atlantoaxial dislocation with an old type II odontoid fracture. Spine J. 2014;14(10):2518-2520.

22. Meng $\mathrm{H}, \mathrm{Gao} \mathrm{Y}, \mathrm{Li}$ M, et al. Posterior atlantoaxial dislocation complicating odontoid fracture without neurologic deficit: a case report and review of the literature. Skeletal Radiol. 2014;43(7):1001-1006.

23. Riouallon G, Pascal-Moussellard H. Atlanto-axial dislocation complicating a type II fracture. Reduction and final fixation. Orthop Traumatol Surg Res. 2014;100(3):341-345.

24. Tian NF, Xu HZ, Wu YS, Chi YL. Traumatic atlantoaxial dislocation with type II odontoid fracture. Spine J. 2014;14(6):1067-1069.

25. Corner EM. Rotary dislocations of the atlas. Ann Surg. 1907;45(1):9-26.

26. Krishnan SP. The cervical spine. In: Iyer KM, ed. Trauma Management in Orthopaedics. Berlin: Springer; 2013:173-179.

27. Fielding W, Hawkins RJ. Atlanoaxial rotatory fixation. J Bone Joint Surg Am. 1977;59(1):37-44.

28. Levine AM, Edwards CC. Traumatic lesions of the occipitoatlantoaxial complex. Clin Orthop Relat Res. 1989;239:53-68.

29. Barbagallo GMV, Certo F, Visocchi M, Palmucci S, Sciacca G, Albanese V. Disappearance of degenerative, noninflammatory, retro-odontoid pseudotumor following posterior C1-C2 fixation: case series and review of the literature. Eur Spine J. 2013;22(suppl 6):S879-S888.

30. Shilpakar S, McLaughlin MR, Haid RW, et al. Management of acute odontoid fractures: operative techniques and complication avoidance. Neurosurg Focus. 2000;8(6):1-7.

31. Pal D, Sell P, Grevitt M. Type II odontoid fractures in the elderly: an evidence-based narrative review of management. Eur Spine J. 2011;20(2):195-204.

32. Mummaneni PV, Haid RW. Atlantoaxial fixation: overview of all techniques. Neurol India. 2005;53(4):408-415.
33. Gupta S, Goel A. Quantitative anatomy of the lateral masses of the atlas and axis vertebrae. Neurol India. 2000;48(2):120-125.

34. Goel A, Desai K, Mazumdar D. Atlantoaxial fixation using plate and screw method: a report of 160 treated patients. Neurosurgery. 2002;51(6):1351-1356.

Disclosures and COI: The authors declare no conflicts of interest. The institutional review board (IRB) of the University of California, Irvine, deemed this study to constitute a nonresearch endeavor, which therefore did not require IRB approval. Patient confidentiality has been protected according to the US Health Insurance Portability and Accountability Act (HIPAA) and in accordance to the tenets established by the Declaration of Helsinki for human subjects. The patient provided verbal consent after being asked if the material in this case report may be published.

Corresponding Author: Arif Musa, MS, School of Medicine, Wayne State University, 540 East Canfield Street, Detroit, MI 48201. Phone: (313) 577-1450; Fax: (313) 577-1457; Email: arif.i. pendi@gmail.com.

Published 22 February 2019

This manuscript is generously published free of charge by ISASS, the International Society for the Advancement of Spine Surgery. Copyright (c) 2019 ISASS. To see more or order reprints or permissions, see http://ijssurgery.com. 